\title{
Exercise Physiology
}

National Cancer Institute

\section{Source}

National Cancer Institute. Exercise Physiology. NCI Thesaurus. Code C39940.

Exercise Physiology is the identification of physiological mechanisms underlying physical activity, the comprehensive delivery of treatment services concerned with the analysis, improvement, and maintenance of health and fitness, rehabilitation of heart disease and other chronic diseases and/or disabilities, and the professional guidance and counsel of athletes and others interested in athletics, sports training, and human adaptability to acute and chronic exercise. (American Society of Exercise Physiologists) 